\title{
INVESTIGATION OF FRAYING IN TEXTILE REINFORCEMENTS FOR COMPOSITES
}

\author{
Yousef Badripour, François Robitaille \\ Department of Mechanical Engineering \\ University of Ottawa \\ Ottawa, Canada
}

\begin{abstract}
This paper discusses the fraying of textile reinforcements upon preforming. The paper also introduces a method for quantifying the fraying characteristics of fabrics. Six different fabrics including three carbon fabrics and three glass fabrics were tested. Digital microscopy was also used for measuring the structures of the fabrics tested. The relation between the structures and fraying is discussed.
\end{abstract}

Keywords- textiles; composites; fraying; yarn loss

\section{INTRODUCTION}

Fibre reinforced polymer matrix composites are increasingly used in numerous applications. However, a lack of established standard characterization methods for the dry fabrics used in manufacturing these composites preclude the use of quantitative methods for analyzing and predicting the manufacturing operations. Upon preforming, different fabrics behave in different ways, making it difficult to plan manufacturing efficiently. Each element of the behaviour of these textiles demands a reproducible testing method. Some elements have been investigated thoroughly [1]; however, others still lack proper testing methods. Knowledge of the fraying characteristics of carbon and glass fabrics upon cutting and handling is important in manufacturing; however, no established testing method exists for assessing it. Although some work was done towards that aim, leading to the yarn pull-out test [2] or the inter-yarn friction test [3], such tests mostly measure friction between yarns when subject to pulling or shear; however, yarns fraying from the edges upon draping on moulds is a recurring phenomenon. This paper introduces a reproducible test method for measuring fraying in industrial reinforcement fabrics.

\section{INDUSTRIAL CONTEXT}

When draped, industrial fabrics can show fraying around the edges. The amount of fraying can vary with the fabric type, fabric architecture and mould geometry. A typical situation when fraying can occur is the darting of a fabric, which is done to facilitate the draping of a mould of complex geometry [4]. "Fig. 1" and "Fig. 2" show two different fabrics after being cut and draped on a mould. More complex mould geometries result in higher shear and more fraying, eventually making the draping process more problematic.

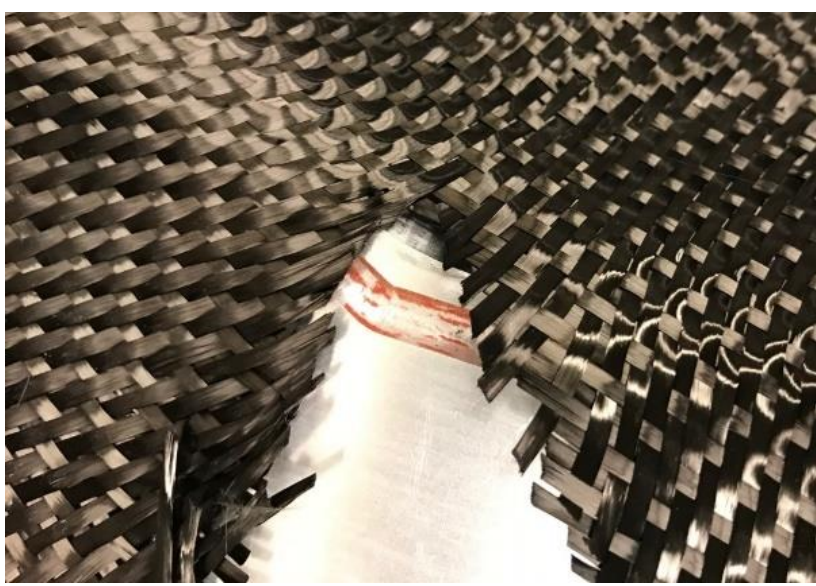

Figure 1. Fraying around edges after cutting and draping, 5-harness carbon fabric

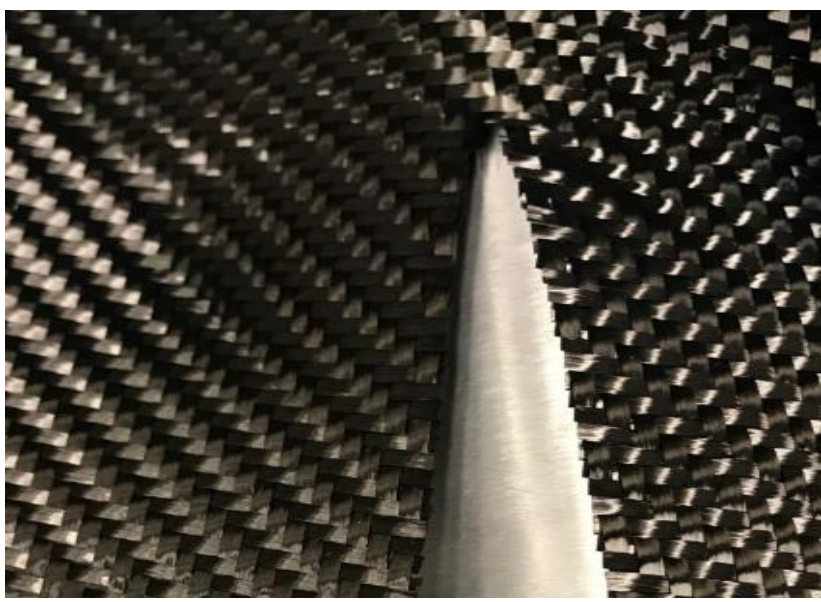

Figure 2. Fraying around edges after cutting and draping, twill carbon fabric 


\section{APPARATUS AND METHODOLOGY}

A testing rig featuring a $3.81 \mathrm{~cm}$ (1.5 in) circular platen supported by a $0.95 \mathrm{~cm}(3 / 8 \mathrm{in})$ rod is mounted into a spinner with an adjustable speed. Tests reported in this paper were conducted at a spinning speed of 1500 RPM. Circular fabric specimens measuring $15.24 \mathrm{~cm}$ (6 in) in diameter were placed on the platen. Double-sided General Sealants Inc tape covered the whole surface of the circular platen and held the fabric onto it. Samples were spun at the aforementioned speed for 3 seconds. Inertial forces caused some yarns to dislodge from the edges. Lost yarns were quantified using mass and area loss. Tests were run 5 times for each fabric and average losses are reported in Table 1 and Table 2.

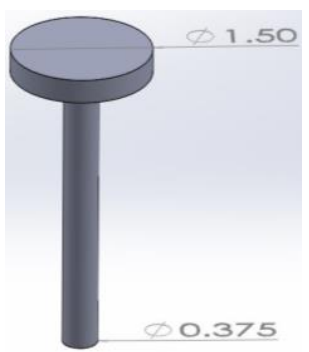

(a)

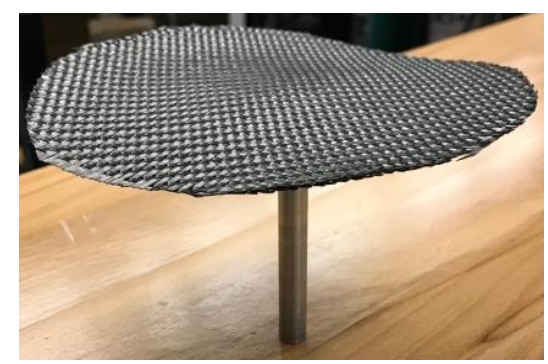

(b)
Figure 3. Test rig (a) and fabric specimen mounted on the rig (b)

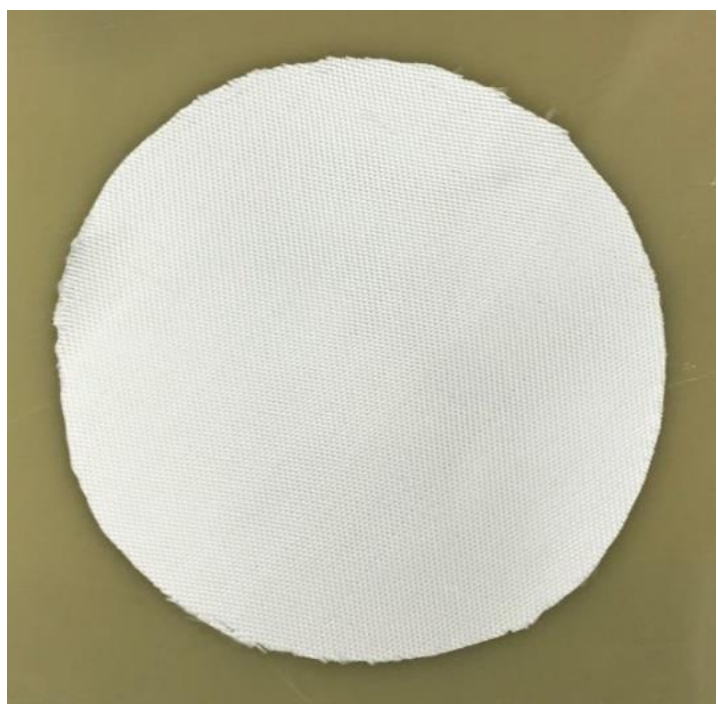

Figure 4. 8-harness glass fabric specimen, before test

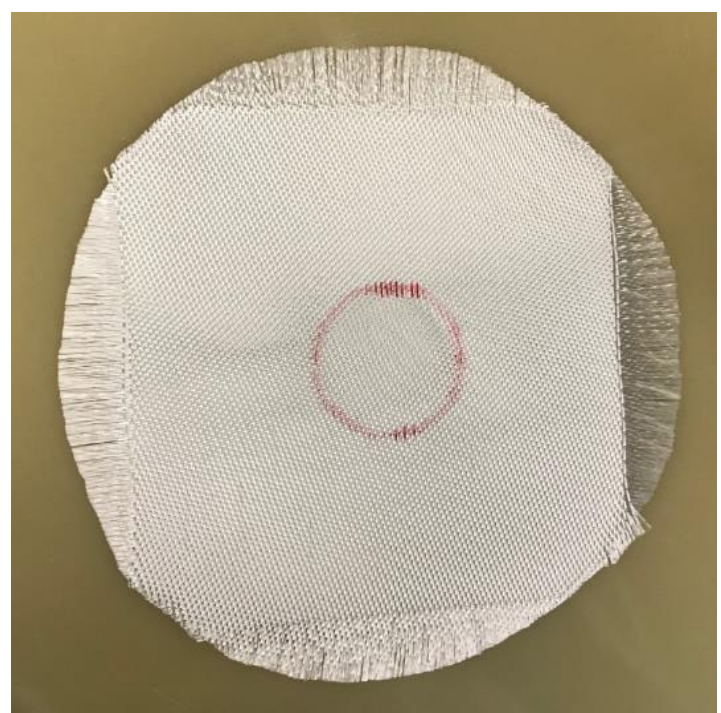

Figure 5. 8-harness glass fabric, after test

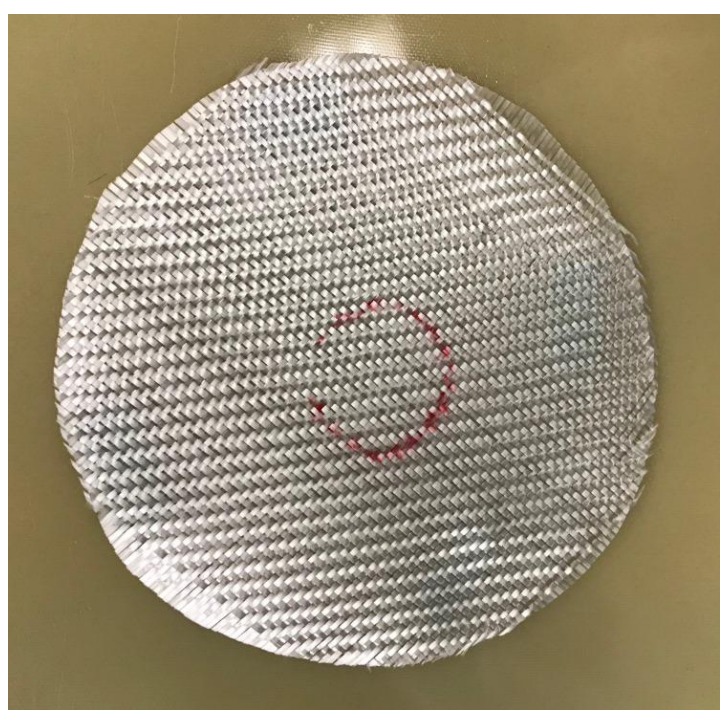

Figure 6. Twill glass fabric after test

The mass of each specimen was measured before and after the test, using a Smart weight dual platform scale with $200 \mathrm{~g}$ capacity and $\pm 0.001 \mathrm{~g}$ accuracy. Mass loss is reported as an average.

The area of the specimen before the test and the nonfrayed area after the test were measured using the ImageJ software. Area loss is reported as an average for each fabric.

Topographies were determined using Keyence VHX-6000 series digital microscope. Effects of maximum height and textiles patterns are assessed. 


\section{RESULTS}

Table 1 and Table 2 give fabrics information such as architecture, surface density as well as yarn count. It also lists results for mass loss, area loss and standard deviations for both measurements.

"Fig. 7" to "Fig. 12" illustrate topographies for the fabrics tested. These topographies returned maximum value of 192 $\mu \mathrm{m}$ in the twill glass and $195 \mu \mathrm{m}$ in the twill carbon with regard to their surface pattern range in the $\mathrm{z}$ axis direction. The value was $237.2 \mu \mathrm{m}$ for the 8 -harness glass fabric. Higher values indicated a higher crimp factor for a given fabric.

TABLE 1. TEST RESULTS FOR GLASS FABRICS

\begin{tabular}{|c|ccc|}
\hline Fabric & Glass & Glass & Glass \\
Architecture & Plain & Twill & 8-harness \\
$\begin{array}{c}\text { Surface density } \\
\left(\mathbf{g} / \mathbf{m}^{2}\right)\end{array}$ & 304 & 300 & 296 \\
$\begin{array}{c}\text { Yarn count } \\
(\text { yarn/cm) }\end{array}$ & 5.55 & 6.45 & 22.42 \\
$\begin{array}{c}\text { Mass loss (\%) } \\
\text { Area loss (\%) }\end{array}$ & 43.15 & 1.39 & 11.23 \\
$\begin{array}{c}\text { Mass loss standard } \\
\text { deviation (\%) }\end{array}$ & 77.07 & 6.04 & 20.68 \\
$\begin{array}{c}\text { Area loss standard } \\
\text { deviation (\%) }\end{array}$ & 6.63 & 15.83 & 10.24 \\
\hline
\end{tabular}

TABLE 2. TEST RESULTS FOR CARBON FABRICS

\begin{tabular}{|c|c|c|c|}
\hline Fabric & Carbon & Carbon & Carbon \\
\hline Architecture & Twill & $\begin{array}{l}\text { 5-harness with } \\
\text { binder }\end{array}$ & Stitched \\
\hline $\begin{array}{l}\text { Surface density } \\
\qquad\left(\mathrm{g} / \mathrm{cm}^{2}\right)\end{array}$ & 408 & 368 & 288 \\
\hline $\begin{array}{l}\text { Yarn count } \\
(\text { yarn/cm) }\end{array}$ & 5 & 4.54 & 2 \\
\hline Mass loss (\%) & 3.03 & 1.84 & 1.09 \\
\hline Area loss (\%) & 7.20 & 4.75 & 3.39 \\
\hline $\begin{array}{c}\text { Mass loss standard } \\
\text { deviation }(\%)\end{array}$ & 17.82 & 17.39 & 9.17 \\
\hline $\begin{array}{c}\text { Area loss standard } \\
\text { deviation }(\%)\end{array}$ & 18.89 & 33.68 & 26.84 \\
\hline
\end{tabular}

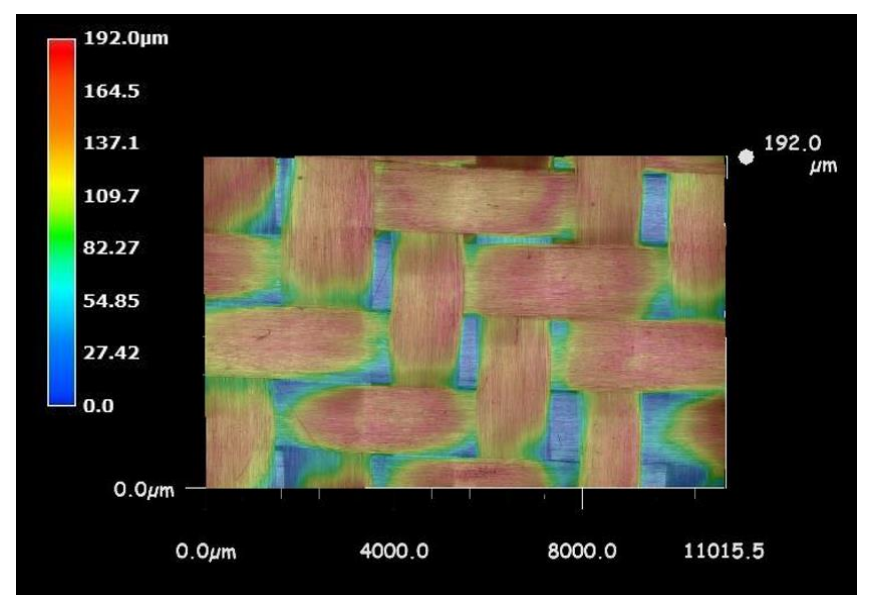

Figure 7. Topography of twill glass fabric

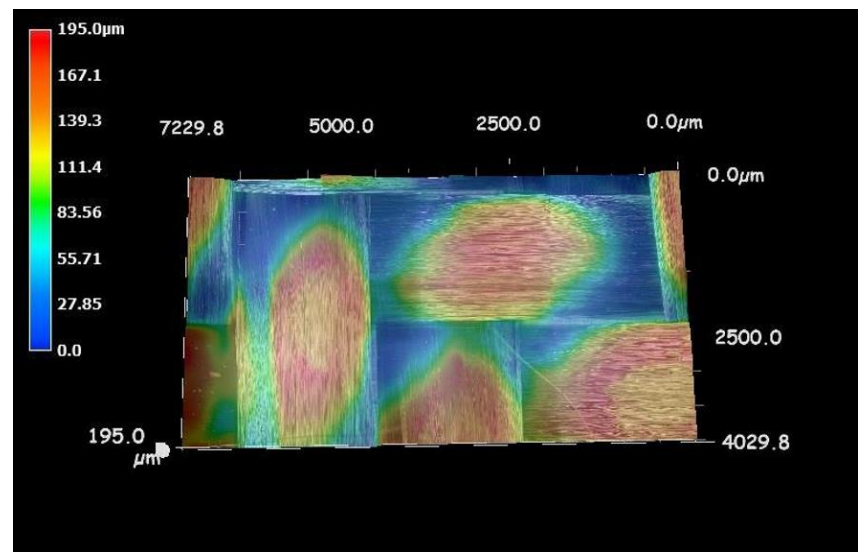

Figure 8. Topography of twill carbon fabric

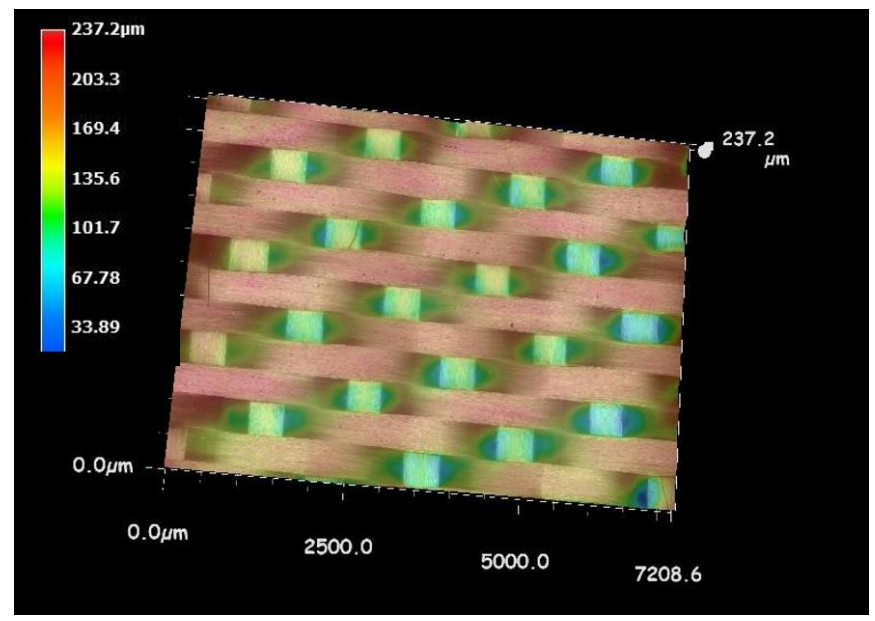

Figure 9. Topography of 8-harness glass fabric 


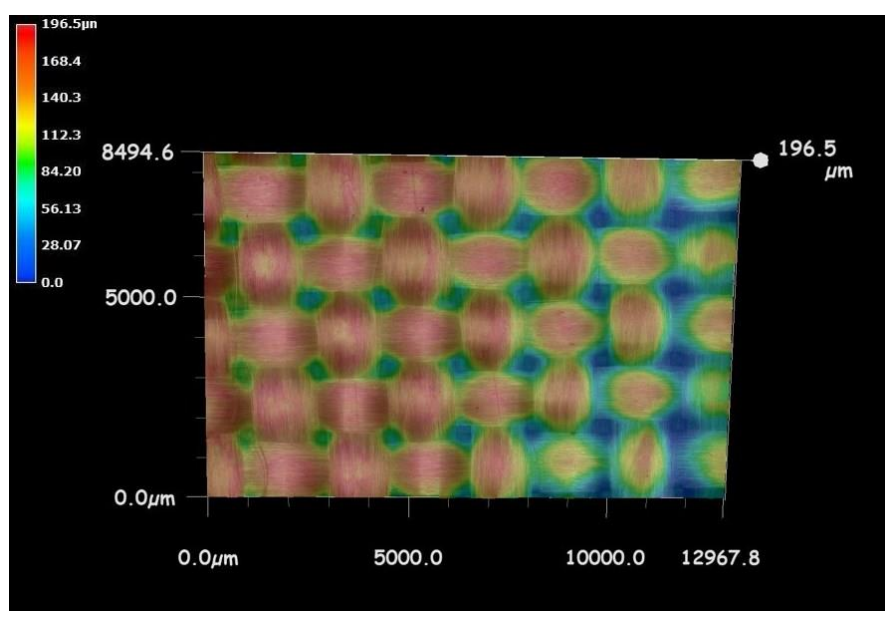

Figure 10. Topography of plain glass fabric

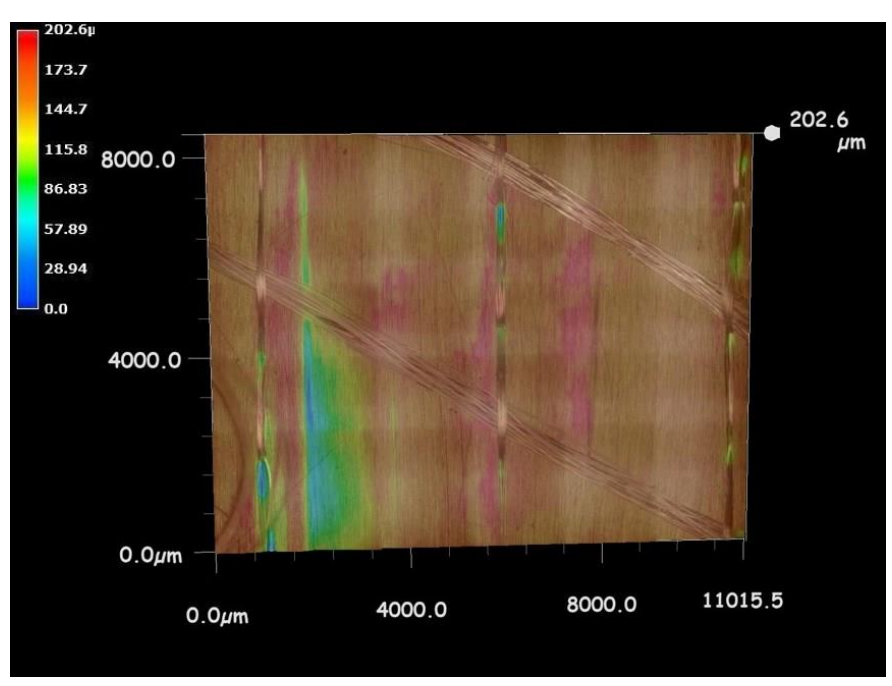

Figure 11. Topography of stitched carbon fabric

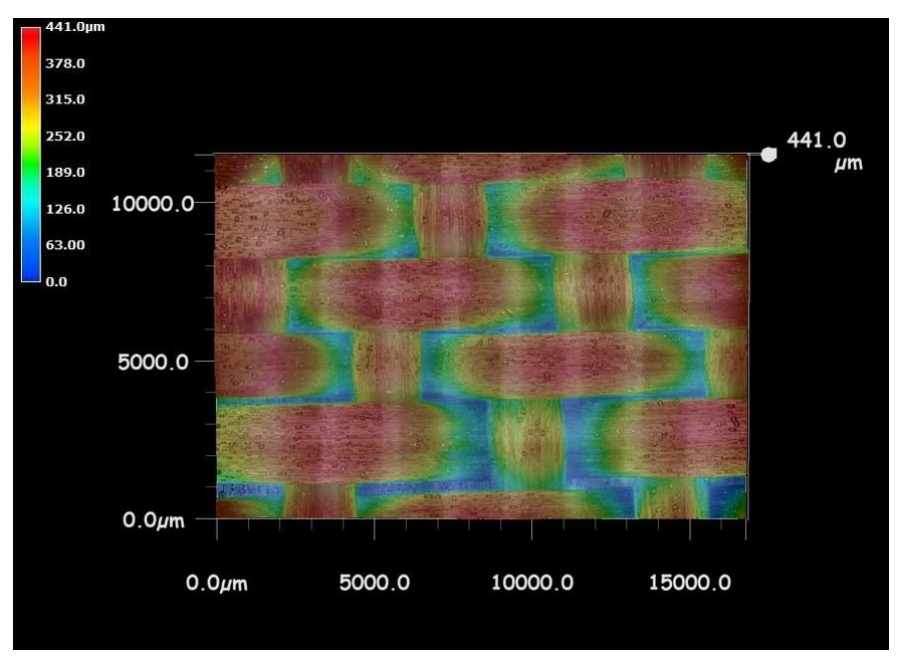

Figure 12. Topography of 5-harness carbon fabric with binder
"Fig. 13" shows the results from Table 1 and Table 2 comparing the mass loss (\%) and area loss (\%) for all fabrics.

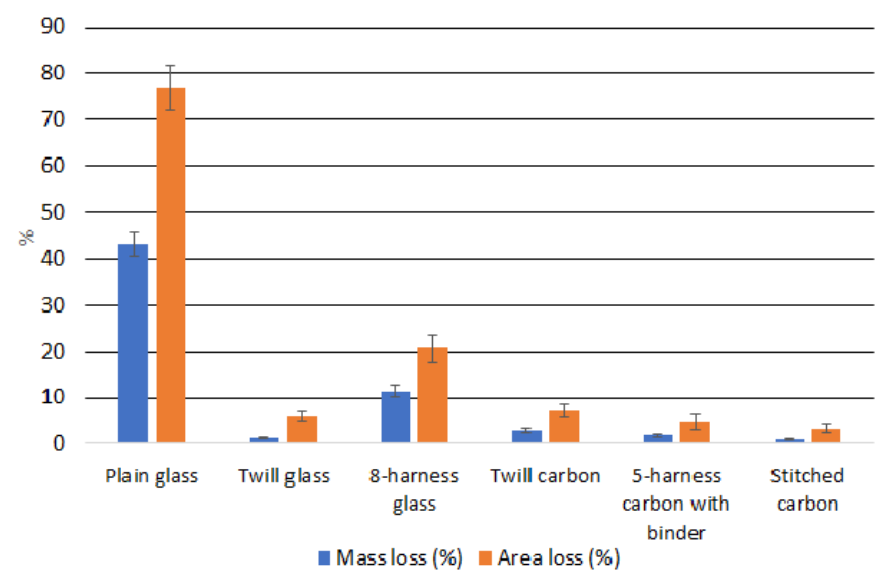

Figure 13. Mass loss and area loss chart for all tested fabrics

\section{DISCUSSION}

Test results for twill glass fabric, twill carbon fabric, 5harness carbon fabric with binder and stitched carbon fabric show limited yarn loss. On the other hand, results for the 8harness glass fabric, showed moderate amounts of yarn loss, and the plain glass fabric showed high amounts of yarn loss. This high amount of yarn loss in plain glass fabric could be due to low amount of inter-yarn friction as well as the plain structure itself. It can be concluded that twill fabrics show a high resistance to fraying. Also, the use of a binder on the fabric and the presence of stitching in fabrics prevent edge fraying efficiently.

The stitched carbon fabric used in testing had fibers extending along $45^{\circ}$ and $-45^{\circ}$ directions with a stitch along the $0^{\circ}$ direction. This fabric predictably returned the minimum amount of yarn loss, confirming that stitching can be a potent solution to the occurrence of fraying in some cases [5].

The analysis of fabric topography delivered information regarding each fabric crimp factor. Twill structured fabrics showed less crimp than the 8-harness one. Varying amounts of crimp can lead to differences in triggering of yarns sliding relatively to each other [6]. Tables 1 and 2 support this claim, as higher mass and area losses are seen for the 8-harness fabric compared with the twills, and similar figures were seen for both twill carbon and twill glass fabrics.

"Fig. 1", which illustrates noticeable fraying for the 5harness carbon fabric, and Table 1 which reports the second highest yarn loss for the 8-harness glass fabric, it can show that yarns in satin fabrics are more likely to slip from the edge.

Results for each fabric showed limited variability notably for the mass loss measurements. However, using an automated 
cutting machine [7] for preparing the specimens, would lead to more accurate specimens resulting in more repeatable results.

\section{CONCLUSION}

This work introduced a reproducible testing method for measuring yarn loss in carbon and glass fabrics with minimum variability in results aiming at quantifying fraying. The impact of some fabrics attributes such as architecture, stitching and presence of a binder on yarn loss was observed and discussed.

\section{REFERENCES}

[1] J. Cao et al., "Characterization of mechanical behavior of woven fabrics: Experimental methods and benchmark results," Compos. Part A Appl. Sci. Manuf., vol. 39, no. 6, pp. 1037-1053, 2008.

[2] Z. Dong and C. T. Sun, "Testing and modeling of yarn pull-out in plain woven Kevlar fabrics," Compos. Part A Appl. Sci. Manuf., vol. 40, no. 12, pp. 1863-1869, 2009.

[3] X. S. Zeng, V. B. C. Tan, and V. P. W. Shim, "Modelling inter-yarn friction in woven fabric armour," Int. J. Numer. Methods Eng., vol. 66, no. 8, pp. 1309-1330, 2006.

[4] N. Metaaphanon, Y. Bando, B. Y. Chen, and T. Nishita, "Simulation of tearing cloth with frayed edges," Comput. Graph. Forum, vol. 28, no. 7, pp. 1837-1844, 2009.

[5] K. Bilisik and M. Korkmaz, "Multilayered and Multidirectionally-stitched aramid Woven Fabric Structures: Experimental Characterization of Ballistic Performance by Considering the Yarn Pull-out Test," Text. Res. J., vol. 80, no. 16, pp. 1697-1720, 2010.

[6] S. Backert, "The Relationship Between the Structural Geometry of a Textile Fabric and Its Physical Properties: Part II: The Mechanics of Fabric Abrasion," Text. Res. J., vol. 21, no. 7, pp. 453-468, 1951.

[7] A. Angerer, C. Ehinger, A. Hoffmann, W. Reif, G. Reinhart, and G. Strasser, "Automated cutting and handling of carbon fiber fabrics in aerospace industries," 2010 IEEE Int. Conf. Autom. Sci. Eng. CASE 2010, pp. 861-866, 2010. 